\title{
Experiencias de lectura literaria en educación básica: Papelucho de Marcela Paz, un estudio de caso
}

Reading

experiences in

elementary school:

Papelucho written

by Marcela Paz, a

case study
Experiências de

leitura literária na

educação básica:

Papelucho de

Marcela Paz, um

estudo de caso

Ximena Troncoso Araos* ORCID: https://orcid.org/0000-0002-1961-2977

Macarena Navarro Carvallo** ORCID: https//orcid.org.0000-0001-9959-028X

\section{(c) (1) (5) \\ Para citar este artículo \\ Troncoso, X. y Navarro, M. (2019). \\ Experiencias de lectura literaria en educación básica: Papelucho de \\ Marcela Paz, un estudio de caso. \\ Folios, 50, 97-110. \\ doi: 10.17227/Folios.50-10223}

Artículo recibido

$10 \cdot 05 \cdot 2018$

Artículo aprobado

$25 \cdot 01 \cdot 2019$

* Universidad Católica del Maule. Correo electrónico: xtroncos@ucm.cl

** Universidad Católica del Maule. Correo electrónico: mnavarroc@ucm.cl 


\section{Resumen}

El objetivo de esta investigación es describir experiencias de lectura literaria en educación básica, focalizándose en la obra Papelucho, de Marcela Paz, el mayor clásico de la literatura infantil chilena. La metodología aplicada es cualitativa, de diseño descriptivo interpretativo. Se realizaron cinco sesiones de lectura y diálogo sobre uno de los libros de la serie y una entrevista grupal. La información se recogió a través de registros fílmicos, registros de audio y documentos escritos, cuyos contenidos se analizaron con una matriz que contempló aspectos literarios y fases del proceso lector. Los resultados de la investigación se sintetizaron en tres aspectos: lenguaje literario, humor y valoración del libro. Estos evidenciaron la actualidad y trascendencia de la obra por las experiencias de lectura que generó en las estudiantes, quienes comprendieron y se identificaron con el lenguaje, disfrutaron del humor en distintas modalidades y empatizaron con el personaje protagónico. Tales experiencias confirman también que una obra de calidad literaria pertinente al mundo de los lectores puede contribuir a que desarrollen lecturas ricas en sentido y que despierten su interés.

\section{Palabras clave}

literatura infantil; literatura latinoamericana; lectura; enseñanza de la literatura

Abstract

The following investigation intends to describe different literary reading cases in elementary school focused on Papelucho, the greatest Chilean children's classic written by Marcela Paz. It was conducted under the qualitative method with descriptive-interpretive design. Five sessions were held to read and discuss about one of the books of the series, plus, one group discussion. The information was collected through video and audio recordings and written documents which were analyzed using a matrix that considered both, literary aspects and the stages of the reading process. The results of the research were summarized into three different categories: literary language, humor, and appraisal of the book. The results showed how contemporary and transcendent this piece of work still is, taking into account the reading experiences of the students who understood and identify themselves with the language, enjoyed the humor in different styles and empathized with the main character as well. Such experiences also confirm that a work of high literary quality and pertinent to the reader's world can contribute to develop his reading process, make it more meaningful and awaken his interest.

Keywords

Children's literature, Latin American literature, reading, literary teaching

\section{Resumo}

0 objetivo desta pesquisa é descrever experiências de leitura literária na educação básica, enfocando 0 trabalho Papelucho, de Marcela Paz, o maior clássico da literatura infantil chilena. A metodologia aplicada é qualitativa, de desenho descritivo interpretativo. Cinco sessões de leitura e diálogo foram realizadas em relação com um dos livros da série e uma entrevista em grupo. As informações foram coletadas por meio de registros de filmes, registros em áudio e documentos escritos, cujos conteúdos foram analisados com uma matriz que incluiu aspectos literários e fases do processo de leitura. Os resultados da pesquisa foram sintetizados em três aspectos: linguagem literária, humor e valoração de livros. Estes evidenciaram a atualidade e relevância do trabalho pelas experiências de leitura que gerou entre os alunos, que entenderam e se identificaram com a linguagem, desfrutaram do humor em diferentes modalidades e se solidarizaram com o protagonista. Tais experiências também confirmam que um trabalho de qualidade literária relevante para o mundo dos leitores pode contribuir para o desenvolvimento de leituras ricas em sentido e que despertem seu interesse.

\section{Palavras-chave}

literatura infantil; literatura latino-americana; leitura; ensino de literatura 


\section{Introducción}

Uno de los desafíos actuales de las investigaciones sobre lectura literaria es estudiar los textos desde su especificidad. En esta línea, el campo de la lectura desde una perspectiva literaria ha recibido poca atención. Por otra parte, la estética de la recepción y parte de la semiótica relevaron el papel del lector: los conceptos “creatividad de la recepción” (Iser, 1987) y "obra abierta” (Eco, 1981) sintetizan la idea de que los significados de una obra se construyen en el acto de lectura, en la relación texto y lector. De ahí que conocer cómo los lectores interactúan con las obras contribuye a una mayor comprensión de la literatura y de la lectura. Esto aporta a la conformación del canon y del corpus, especialmente si se piensa en el contexto escolar.

Un tipo de obras que amerita su estudio son aquellas consideradas clásicas, como lo es la serie novelística Papelucho, de la escritora chilena Marcela Paz, Premio Nacional de Literatura (1982). La serie Papelucho consta de doce libros, cuyas publicaciones se inician con Papelucho, en 1947, y culminan con Papelucho, ¿soy dixleso?, en 1974. En ellos, un niño de entre 8 y 9 años cuenta sus aventuras a través de un diario de vida. No obstante la trascendencia de la obra, que ha sido traducida al inglés, francés, italiano, japonés, ruso y griego, no existen estudios de recepción lectora sobre ella, y son escasos los estudios literarios.

Si Papelucho se constituye en un clásico por las experiencias de lectura que genera, interesa conocer la recepción de los lectores infantiles, y saber si, como clásico, "sobrevive a su presente, a su contexto e, incluso, a su autor" (Cerrillo, 2015 p. 89). Por tanto, el objetivo de este estudio es describir experiencias de lectura en relación con la obra $M i$ hermano hippie, por Papelucho, por estudiantes de sexto año de educación básica, focalizándose en el lenguaje literario, el humor y la valoración de la obra.

Se entiende por experiencia de lectura la "transacción entre el lector y el texto del autor", en que forma y contenido son inseparables, y en que lo cognitivo y lo emocional se conjugan en la actividad lectora (Rosemblatt, 2002, p. 62). De ahí que los aspectos identificados como humor, lenguaje literario y valoración de la obra se imbriquen. Al reparar en la relación entre literatura y lector, no solo se ha de considerar la competencia literaria, con el desarrollo de habilidades y conocimientos literarios (Culler, 1979; Mendoza, 2004; Colomer, 2010), sino también la dimensión afectiva (Rosemblat, 2002; Sanjuán, 2011; Munita, 2011), y a los lectores como sujetos sociales, pertenecientes a un contexto cultural que incide en su forma de ver el mundo y de leer (Bronckart, 2007; Bombini, 2005; Cuesta, 2006).

Los estudios en didáctica de la lectura literaria coinciden en que un objetivo central de la enseñanza de la literatura es valorar las obras. Entendemos por "valorar literariamente" emitir una opinión sobre la obra de manera global o parcial considerando criterios de gusto personal y características del texto. Idealmente, la valoración literaria considera la argumentación, por tanto, la fundamentación de las opiniones. Esto supone comprender, interpretar y establecer relaciones con las experiencias personales y el mundo interior y exterior del lector. La valoración ha de marchar a la par con el propósito de cultivar el gusto por la lectura. Al decir de Lomas, la formación literaria ha de aspirar a "crear el deseo de leer, la curiosidad por los textos, los vínculos afectivos con ellos" (2014, p. 6).

Los textos literarios para niños también han de tener espesor artístico, con gestión del lenguaje verbal y no verbal y los significados que vehiculan. Aunque las obras no utilicen recursos formales exclusivos de lo literario, enfatizan ciertos aspectos, como son la polisemia, la ficción y la función estética, en diálogo con los géneros de la tradición, lo que puede traducirse como continuidad o ruptura.

El humor es otro aspecto que consideramos interesante y relevante a la hora de seleccionar obras de literatura infantil, además de ser un componente importante en la serie Papelucho. Como lo afirma Soriano (1995), desde sus primeras manifestaciones, la literatura infantil se ha esforzado por utilizar la comicidad: a veces como un respiro, como un alto en el relato, y otras veces como procedimiento sistemático de creación, con el propósito de distender o 
de corregir (pp. 358-370). Precisamente, Papelucho nace a contrapelo de una literatura infantil carente de humor. Al respecto, Ana María Larraín enfatiza: "el humor de Papelucho estriba justamente en los aspectos de su personalidad que carecen de humor pues le son consubstanciales, y divierten a quien puede mirarlos desde fuera" (2009, p.183).

La serie Papelucho se inscribe en el verosímil realista y en el género que denominamos relato de aventuras cotidianas, cuyas historias se centran en situaciones relativas a la experiencia de los niños y su entorno de vida: familia, amigos, escuela (Troncoso y Rubio, 2015). Los personajes viven peripecias que desestabilizan su rutina e imprimen en ella un punto de inflexión que las vuelve de interés narrativo. Aunque se enfocan en las aventuras de personajes infantiles, también encontramos algún grado variable de sicologismo, de incursión en la interioridad del personaje.

\section{Método}

La investigación es de tipo cualitativa y corresponde a un estudio de caso (Pérez Serrano, 2004), puesto que se trata de describir y comprender los significados que los sujetos construyen en relación con un objeto hecho de lenguaje, específicamente, una obra literaria. El carácter descriptivo-interpretativo de la investigación permite la construcción de sentido en la relación lector-texto y texto-lector. Como criterios para determinar el caso, se consideró que fuera un curso de educación básica de escuela pública del sector urbano de la comuna de Curicó, en Chile. La escuela se seleccionó por criterio de accesibilidad, pues la directora y el profesor mostraron interés y accedieron a que se realizara el estudio, así también las alumnas, en cuyo caso sus apoderados firmaron consentimientos. Nos interesó atender a lo que ocurre con estudiantes de escuela pública por corresponder en su mayoría a niños de familias de estratos bajos y medios bajos, y cuyos resultados en las pruebas estandarizadas son más bajos en relación a escuelas subvencionadas o particulares. El grupo lo conformaron 25 alumnas de sexto básico. Se optó por este nivel a razón de las características de la obra Papelucho en el plano de la historia y del discurso, y teniendo en consideración los criterios de selección de textos que define Gemma Lluch para niños desde doce años: "Lectores autónomos, que leen con destreza e independencia y eligen los textos pensando más en el argumento que en la imagen. Buscan razones para explicarlo todo y prefieren los temas de la vida real porque se sienten identificados con los problemas e inquietudes de los protagonistas" (2010, p. 75).

Para la recopilación de datos se utilizó el método de observación participante, con cuatro sesiones de lectura que se enmarcaron en los horarios de las clases de Lenguaje y Comunicación con la finalidad de mantener el contexto regular de aula. En una quinta sesión, se realizó una entrevista grupal a seis estudiantes que se mostraron como lectoras activas, esto es, que se destacaron en la calidad de sus respuestas y en sus comentarios sobre el texto durante la mediación lectora.

La validez del diseño se atendió por la combinación de estrategias: varias técnicas de recopilación de información (observación, escritos de las estudiantes y grupo focal), datos registrados de manera mecánica (registros fílmicos y de audio), y la posición de un investigador participante y múltiple (McMillan y Schumacher, 2005, pp. 215-216). El presente trabajo posee un "valor de verdad" en el sentido de "credibilidad", dada por la "observación persistente" en el tiempo debido a la permanencia de las autoras en el campo de investigación durante todas las sesiones (Bisquerra, 2009, p. 289), en donde cumplieron un papel activo como mediadoras de la lectura, acompañadas por el profesor de la asignatura, con el objeto de conseguir un equilibrio entre controlar la mediación y cautelar la familiaridad del contexto.

El trabajo de campo consistió en la aplicación de un diseño orientado a estudiar la recepción de la obra por parte de las estudiantes, el que contempló guiones para cada una de las cuatro sesiones de lectura en voz alta y conversación sobre y a partir de la obra seleccionada (Chambers, 2014). Esto, con el fin de que las estudiantes pudieran "establecer un tránsito desde la recepción individual hasta la recepción en el seno de una comunidad cultural 
que la interpreta y valora" (Colomer, 2010 p.199). Se alternó la lectura en aula y la lectura en casa, de modo tal que al final de la cuarta sesión se concluyera la lectura de toda la novela, que estuvo a cargo de los docentes (autoras y profesor del curso) de manera alternada y, en menor medida, de algunas estudiantes. Luego de ello, se generaron diálogos en base a un guion de preguntas relacionadas con los objetivos de la investigación y la matriz de análisis, que fue variando a partir de las respuestas de las estudiantes. La información de las cuatro sesiones se recogió a través de la filmación, los textos de las estudiantes y una carta dirigida a Papelucho redactada por cada una de ellas. Finalmente, el grupo focal permitió profundizar y precisar la información obtenida durante las sesiones.

Una vez recopilada la información, se realizó su transcripción y su análisis a través de una matriz de doble entrada, cuyas categorías se establecieron tomando en cuenta, por una parte, aspectos literarios de la obra, como componentes narrativos, temas, elementos lingüísticos y discursivos y el humor; por otra parte, consideramos fases del proceso de recepción lectora: precomprensión, comprensión e interpretación (Mendoza, 2004). A partir del análisis de la matriz, los resultados se sintetizaron en tres aspectos: lenguaje literario, humor y valoración de la obra. Para ello, se recurrió a la técnica de análisis de contenido, entendida, en su vertiente cualitativa, como análisis de textos que proporcionan datos que admiten una "lectura directa del sentido manifiesto, al pie de la letra, y soterrada del sentido latente, entresacado del otro" (Ruiz, 2012, p. 195). En esta matriz se vació la información proveniente de las intervenciones de las estudiantes registradas en las filmaciones, los escritos de las alumnas y el grupo focal, lo que permitió obtener una descripción consistente de la recepción de la obra por parte de las estudiantes. Al analizar el contenido del discurso de las alumnas, también se reparó en el lenguaje no verbal, como "técnica suplementaria" que permitió dar mayor sustento a la interpretación de los datos, en tanto el lenguaje corporal resultaba congruente con lo que las alumnas decían (McMillan y Schumacher, 2005, p. 471).

\section{Resultados}

A continuación, se presentan los resultados de los análisis obtenidos de las respuestas lectoras en función de los aspectos de la matriz: lenguaje literario, humor y valoración de la obra.

\section{Lenguaje literario}

Mi hermano hippie, por Papelucho, de 1971, corresponde al décimo título de la serie. En él su protagonista decide ir en busca de su hermano mayor, un adolescente que adopta un estilo hippie, y se va de casa porque sus padres reprueban su cambio. Alrededor de este eje narrativo, se tejen una serie de aventuras y se tocan distintos temas, como la amistad, las relaciones familiares, la libertad y la igualdad social, sobre las que Papelucho expresa su opinión y sus sentimientos con seriedad y humor.

El diario de vida, que es un texto íntimo, deriva hacia lo público y literario, según se desprende del segundo libro de la serie, Papelucho casi huérfano, en que al inicio de la historia aparece un editor que ha encontrado el diario de Papelucho que un niño le había robado y echado a la basura. Este hombre le cuenta que su diario se publicó y le propone seguir escribiendo. La obra adquiere un carácter metaliterario al referir a la escritura y al libro, como también se aprecia en parte del título del libro seleccionado, "por Papelucho", sobre la que una estudiante señala: "Papelucho escribe así como un diario, y entonces, los diarios son los libros que salen" (S. E 1)1. Las estudiantes distinguen la instancia narrativa entre Papelucho y Marcela Paz, respectivamente. También reconocen la relación intertextual genérica, pues la mayoría de las niñas había escrito diarios de vida, algunos digitales. Ellas coinciden con Papelucho en la escritura del diario de vida, porque les ofrece la posibilidad de exteriorizar algo que no pueden o no quieren contar a nadie, relatar sus vivencias y expresar emociones y sentimientos. El diario tiene un carácter catártico, liberador, a la vez que placentero. Por tanto, el diario apócrifo o ficcional resulta atractivo porque está en la órbita de experiencias

1 Las citas están codificadas de la forma siguiente: $S$, sesiones de lectura; G. F., grupo focal; Es., escritos; E, estudiante. 
significativas de las niñas como escritoras o como lectoras furtivas de diarios ajenos.

El escritor chileno Alberto Fuguet relata su experiencia de lectura de Papelucho a los doce años, luego de que su familia retornara a Chile en 1975: "Papelucho (...) se transformó, de inmediato, en mi álter ego. Pero había algo más, algo no menor: Papelucho hablaba (en rigor, escribía) en un español creíble que, por eso mismo, me permitía, a su vez, creerle todo lo que me confidenciaba" (2001, párr. 2).

Las estudiantes manifiestan una visión análoga a la expresada por Fuguet sobre la obra en relación con el lenguaje. Es impresionante cómo Papelucho y la obra resultan tan cercanos para las alumnas: "A veces yo digo ¡ah!, con este yo me podría entender si existiera de verdad. El lenguaje de Papelucho, para mí, no es extraño ni tan raro" (G.F. E 4). Es interesante cómo la obra genera experiencia de lectura, y eso pasa por cómo está escrita, por cómo hablan los personajes y escribe Papelucho. Una estudiante compara lo que le provoca la obra con lo que le pasa o no le pasa con otros libros. La niña explicita el efecto emocional de la escritura y proyecta esa emoción en su propio discurso de manera verbal y gestual cuando se refiere al libro y se reconoce en esta forma de habla, lo que revela la importancia de la dimensión afectiva del lenguaje. La estudiante asocia el efecto emotivo del libro a las variables lingüísticas, específicamente, a la funcional o diafásica, marcada por un registro informal, y a la geográfica, en que se reconoce como chilena: "algunos libros... como que a mí no me dan sentimientos, muchos sentimientos, porque es como... un libro así como formal, así como... no pasa na. Y con el libro de Papelucho, como que ¡ay!, es como... ¡ay!, es de Chile, y yo sé hablar igual que él, y digo muchas palabras igual que él, entonces, como que nos entendemos así" (G. F. E 4).

La literatura de calidad tiene el potencial para conmovernos, asombrarnos, provocarnos o perturbarnos. Si a esto sumamos una mediación que dé lugar a la expresión de ideas, sentimientos y emociones, y que suscite el diálogo, es probable que se genere una conexión entre lectores y obra, como le ocurre a esta niña: "cuando leo el libro, es como si lo hubieran hecho para nosotros, porque ella quizás cuando lo escribía se daba cuenta de cómo hablaban los niños de ahora. Entonces, como que ella, para que uno sintiera ganas de leerlo, le puso esas frases" (G. F. E 6). Se observa que esta alumna es capaz de reflexionar sobre la obra como objeto artístico ficcional, como creación de una escritora a la que le reconoce su perspicacia y empatía para captar y plasmar en la escritura el habla y la sicología infantil. Al respecto, llama la atención que las alumnas perciban que el habla de los personajes infantiles es como la de "los niños de ahora", no obstante el año de publicación del libro.

Es característico de Papelucho, tanto en la serie como en la obra seleccionada, que por momentos emita frases sentenciosas que encierran una filosofía de vida personal, como cuando se aborta el plan de ir a buscar al hermano al observatorio Cerro Tololo. Papelucho dice que trataba de consolarse consolando al Chorizo, para lo cual sentencia: "siempre falla al principio lo que va a resultar después". Indagamos en el sentido que las alumnas otorgan a este enunciado. Una estudiante relaciona la frase con un dicho popular: "Así como que la primera no es la vencida, así como se dice, la tercera es la vencida" (S. E 13). Esta niña construye una conexión a partir de lo que el texto posibilita. Esto muestra que el pensamiento del personaje y del autor implícito no es ajeno a la sabiduría popular, signada por cierto optimismo, el que las alumnas perciben en el protagonista.

Una pregunta que plantea la recepción de Papelucho es qué pasa con el léxico, en especial, con los neologismos, las incorrecciones idiomáticas, los términos con referentes culturales y palabras que han caído en desuso. Durante las sesiones, las estudiantes no manifiestan problemas con el léxico, pues pudieron inferir significados. Esto se confirmó en la entrevista grupal con preguntas focalizadas sobre el significado de algunas palabras.

Tal es el caso de los chilenismos "chori", "choro", "choriflai" y el neologismo "choriflear". Las estudiantes los consideran equivalentes a "bacán", "divertido", y dicen haberlos escuchado. Algo similar ocurre con 
otras palabras de este tipo. Una alumna se refiere a lo familiar que le resulta el lenguaje de la obra, y ejemplifica con el sintagma "pobre gallo", que usa Papelucho para calificar a su hermano. En el castellano chileno abundan los términos y expresiones zoonímicas. La palabra "gallo" corresponde a un registro informal, refiere a un hombre a quien no se conoce o se conoce circunstancialmente, y a veces comporta una connotación despectiva. Por esto, a las alumnas les resulta gracioso que Papelucho se refiera a su hermano de esta forma.

Los neologismos son característicos del lenguaje de Papelucho, y los encontramos en toda la serie. Palabras como "cataclíptico", "chirimpoya" y "astronáutico" son ejemplos de ellos. Este último término, las alumnas lo asocian a "bueno", "feliz", "alegre", de modo que infieren el carácter positivo de esta palabra en la novela. Sobre la palabra cataclíptico se produce el siguiente diálogo durante las sesiones, en el que se aprecia que las estudiantes asignan contenido al significado de la palabra, que en el discurso de Papelucho refiere a un color. La respuesta de las niñas no es "no sé" o "no conozco esa palabra", sino que el término evoca imágenes en ellas.

Med. A: ¿Qué color se imaginan? Color cataclíptico nos dice Papelucho.

E 3.: De varios colores

Med. A: ¿De varios colores?

E 19 Color fuerte

Med. A: Color fuerte ¿Algún color en especial?

\section{E 4: Llamativo}

Med. A: ¿Qué color se imagina?

E 5: Verde

(Min. 15, sesión 1)

Cabe señalar que los neologismos literarios son abiertos semánticamente: el significado que se les asigna se construye en la interacción de los morfemas y lexemas con el contexto semántico y con el bagaje léxico, la cultura y la subjetividad del lector. La recepción de los neologismos confirma la hipótesis de Isabel Ibaceta: "[el neologismo] evidencia una representación de procesos reales de adquisición del lenguaje infantil, lo que, posiblemente, aporta credibilidad a la voz narrativa" (Ibaceta, 2016, p. 71). A su vez, los neologismos inciden en la buena recepción por parte de los lectores infantiles, por el carácter lúdico y humorístico, como ocurre con gran parte de la obra de Roald Dahl (Cheetham, 2016).

Una estudiante recuerda que el profesor había dicho que Papelucho usaba algunas palabras de manera incorrecta, ante lo que la alumna replica: "nosotras entendimos igual" (G. F. E 3). Un ejemplo de las incorrecciones idiomáticas por Papelucho es la palabra "magnesia", en lugar de "amnesia", y la palabra "sulfuroso", que las estudiantes logran asociarla a "sulfurado" por el contexto semántico. Es claro que, a mayor edad, las estudiantes serán capaces de reconocer más las incorrecciones y de reírse de su uso, pues el humor radica aquí en que la palabra se asimila a otro término, pero con un significado distinto, que resulta gracioso en la situación comunicativa en que se inserta.

La recepción de la obra en cuanto al lenguaje evidencia que este libro genera conexión con los lectores infantiles. El vocabulario deformado o precario con que Marcela Paz recrea el lenguaje infantil (Ibaceta, 2016, p. 70) resulta efectivo, pues las niñas lo perciben "como verdadero", a sabiendas de que se trata de ficción.

\section{Humor}

Al indagar cómo funciona el humor de la obra en la lectura, se observa que las estudiantes pudieron experimentar la risa y distensión provocada por algunas situaciones y frases de los personajes.

Un ejemplo de una situación en que funciona el humor se halla cuando el Chori complementa la idea de Papelucho de plantar árboles frutales para solucionar el problema del hambre: su ocurrencia consiste en un "árbol de sopaipillas", el que Papelucho decide inventar. En ese punto, se combina lo serio y lo humorístico, como plantea Cifuentes, a partir de imágenes figurativas de la levedad: "esta imagen además representa de manera simbólica otro concepto, abstracto y no visible, como es la 
perspectiva leve ante la realidad" (2011, p. 29). Aquí, la idea de producir un árbol de sopaipillas representa una imagen leve producto de un acercamiento insólito entre dos palabras de uso cotidiano: árbol y sopaipillas, por lo tanto, las niñas se ríen con este distanciamiento extraño, poco lógico del mundo real, ya que se transforma, como diría Rodari (2012), en "un descubrimiento, una invención, un estímulo excitante" (p. 29).

Otra imagen que evoca una mirada leve en las estudiantes se encuentra en el episodio en que Papelucho entra al alcantarillado, pues encuentran gracioso que el personaje pensara que la soga que le lanzó un bombero para ayudarlo a salir de la corriente es una culebra larga y flaca. En este caso, las niñas se ríen de la forma ingenua en que Papelucho ve el mundo: define el objeto de manera intuitiva y animada. Esto se aprecia también en lo gracioso que resulta para las alumnas que Papelucho piense en lo que ganará si encuentra al hermano: "Y si les da por premiarme, una bicicleta con motor sería chora. Con tal que Javier no apareciera solo antes que yo lo encontrara" (Paz, 2014, p. 11). Este pensamiento contrasta con la escena de preocupación y llanto en casa y con el deseo del propio Papelucho de dar una alegría a todos. La franqueza de Papelucho contribuye a que se lo aprecie como un niño verdadero y no como un "santurrón".

También les gusta y resulta gracioso, aunque raro, que le haga preguntas a la radio y quiera buscar a su hermano en el espacio. Claramente hay una discrepancia entre lo que hace el personaje y lo que harían en su lugar las lectoras; no obstante, les resulta gracioso por la imaginación ingenua del niño:

Med. C: Ahí está. Retomemos algo que dijo, habló de la radio ¿por qué le hace preguntas a la radio? Acá, Paloma.

E 3: Porque no podía contestar las preguntas él mismo, entonces del comienzo empezó [sic] a contestarse las preguntas de la radio.

Med. C: ¿Y les pareció graciosa la situación ?

Est: (En grupo) Sí.
Med. C: ¿Por qué?, Natalia.

E 19: Porque así como que él le hacía la preguntas y la radio le contestaba lo que él quería escuchar, y era como que estaba hablando con otra persona normal.

Med. C: Normal.

E 12: Yo, a veces cuando estoy con mi mamá o con cualquiera, le hago una pregunta o ella me hace una pregunta, y antes de que yo le responda, en la tele siempre dicen la respuesta, dicen sí o dicen no, o dicen no quiero.

(Minuto14, sesión 2)

Otro ejemplo de humor a través de la conciencia infantil ingenua se aprecia cuando la Ji, la hermana menor de Papelucho, en la conversación con los detectives, le pregunta a uno de ellos: “ ¿Te gustaría casarte conmigo cuando sea grande?” (Paz, 2014, p. 96). Al respecto, las estudiantes tienen una visión leve de tal ocurrencia en una niña pequeña porque la proposición resulta descabellada. En palabras de Edgardo Cifuentes, sería de un "proceder confiado en que las acciones no provendrán consecuencias graves o reacciones reprobatorias" (2011, p. 22).

Por otra parte, a las alumnas también les pareció "chistosa" la descripción detallada del vestuario hippie de Javier y el efecto negativo que produce en sus padres cuando llega a la casa, pues "el narrador, al centrar su atención en los detalles de los hechos graves, hace perder la visión de totalidad y construye para sí mismo, y para el lector, una nueva perspectiva de estas situaciones" (Cifuentes, 2011, p. 25).

Otro aspecto del humor que resulta muy divertido para las niñas son los chascos provocados por la ignorancia o torpeza de los personajes, como cuando Papelucho y sus amigos, sin querer, comen sandía con bencina; cuando Papelucho quiebra una baldosa y, en su intento de pegarla con engrudo, se le pega el pantalón en la taza del baño; también cuando se traga una mosca, entre otras situaciones (ver figura 1, Es. E 3). 


\section{De la lectura que hemos hecho en casa y ahora en la escuela me gustó...}

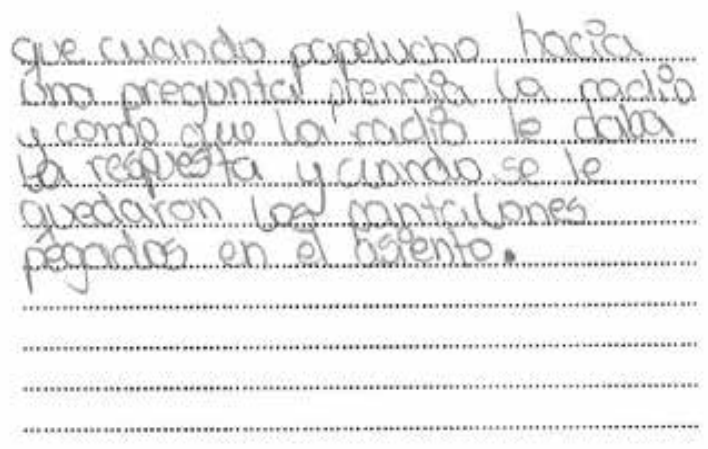

Figura 1. Ejemplo de humor identificado por una estudiante.

Fuente: elaboración propia.

\section{Valoración de la obra}

Sobre el libro en general, todas las estudiantes coincidieron de manera muy expresiva y enfática en que les gustó el libro: "Me gustó todo" (G. F. E 1 y 3). Un aspecto importante que incide en el gusto por el libro es el humor: "porque algunas veces él hacía, por decir, tonteras, que a mí me daban risa" (G. F. E 2). Otro aspecto que resulta del gusto de las alumnas son las aventuras que vive el personaje: "porque es divertido y yo creo que me entraría más interés por leer otros libros" (G. F. E 5). "Me gustaría que las personas entendieran que también hay libros como esos. Que también hay libros que... aventuras, libros así" (G. F. E 3). Es interesante que la estudiante no solo indique lo que le gusta, sino que compare la obra con libros que no resultan de su interés. Otra alumna recomendaría el libro por aspectos valóricos: "porque así verían que el racismo, algunos que son racistas verían que uno no tiene que ser malo con las personas que son pobres, que son morenitas" (G. F. E 6). Este argumento se complementa con la valoración positiva de que Papelucho tenga una relación muy estrecha y de buen trato con Domitila, la empleada de la casa, y que establezca amistad con niños pobres, especialmente con el Chori: "me gusta ese como ser de Papelucho, porque, aunque él sea con mucha plata o con poca, igual va a ser amigo de quien sea, él lo trataba como si él fuera igual que él" (G. F. E 5).
La amistad de Papelucho con niños pobres es un patrón en la serie novelística. Estas amistades entrañan una crítica social elocuente, que en $M i$ hermano hippie se explicita casi al final de la novela, cuando Javier vuelve a la casa y Papelucho discute con él sobre su manera de cambiar el mundo. Las niñas se identifican más con el pensamiento de Papelucho que con el de Javier, pues creen en formas más concretas, centradas en ayudar a otros y en ponerse en el lugar de otros.

La complementariedad entre humor y visión crítica se corrobora en que las estudiantes logran apreciar la crítica explícita e implícita del clasismo y el humor en las formas señaladas. Aquí radica uno de los principales aciertos de la serie Papelucho, y que caracteriza a otros clásicos de la literatura infantil como Alicia en el país de las maravillas, de Lewis Carroll, y las obras de Roald Dahl. Lo grave y el humor, la crítica y la risa regeneradora, no se anulan mutuamente, sino que interactúan en un equilibrio apropiado para los lectores infantiles, que los hace parte del mundo sin transmitir amargura.

La última actividad que realizaron las estudiantes consistió en la escritura de una carta. La idea era que pudieran plasmar sentimientos, opiniones y sensaciones sobre la vida y el mundo de Papelucho, para luego enviarlos a Ediciones Marcela Paz S. A. a través de la web. Fue interesante que las niñas se colocaran 
en la situación imaginaria de que el receptor, en su rol de personaje ficticio, recibiría el mensaje.

El foco principal de sus escritos es la valoración de la obra. Las estudiantes resaltan aspectos positivos del libro de forma unánime, y eso se ve reflejado en expresiones como "te envío este mensaje porque me gustó mucho el libro" (Es. E 6), "te escribo para contarte que me ha encantado tu libro" (Es. E 5), "el libro es muy chistoso y divertido" (Es. E 17), "Papelucho me pareció entretenido tu diario" (Es. E 15), "te quería decir que este ha sido el libro que más me ha gustado" (Es. E 13). Todas estas frases implican un trabajo previo de conversación con el texto, pues la formulación de juicios "solo puede llegar tras las actividades que favorecen un tiempo de reflexión y expansión de la recepción propia, por una parte, y un tiempo de exploración conjunta del significado, por otra" (Colomer, 2012, p. 204).

En segundo lugar, es notorio el agrado que manifiestan por las acciones del protagonista: "me gustó esa parte en la que te metiste en la alcantarilla, donde decías que había cosas extrañas" (Es. E 14). Cuando se trató este episodio del libro, las estudiantes expresaron extrañeza de que Papelucho ingresara a los ductos del alcantarillado; incluso manifestaron sensación de asco y miedo si estuvieran en la misma situación. No obstante, esa extrañeza les resulta divertida.

El aprecio de las alumnas hacia la forma de ser y actuar del Chori reafirma la virtual relevancia de personajes secundarios. El Chori se perfila como referente crucial para las estudiantes como compañero de las aventuras de Papelucho y como gran amigo: "me encantó el amor que le tenía el Chori al Nerón" y "me encantó la forma de ser del Chori, a él le gustaba ir al colegio" (Es. E 18).

Ahora bien, lo que se repite en todas las cartas es la identificación de las estudiantes con Papelucho y el valor especial que le otorgan a su personalidad: "me gustó cómo eras, que siempre ayudaras a los demás y que eras muy optimista" (Es. E 16); "me siento identificada contigo en la manera de pensar y un poco en la personalidad" (Es. E 19); "eres muy bromista, simpático y muy buen amigo” (Es. E 16); "me gustó tu personalidad, que eras amistoso, simpático y travieso" (Es. E 19); "eras simpático, chistoso, curioso, etc."; "quería decirte que sigas siendo como eres, aventurero, curioso, sincero y alegre" (Es. E 8). Sin embargo, una estudiante le aconseja a Papelucho no mentirle a su mamá "me pareció que tu actuar fue de muy mentiroso por no decirle a tu mamá que le sacaste el jamón, la palta, etc." (Es. E 15), debido que eso trajo como consecuencia que culparan a la Domi. En otra ocasión, las niñas mencionan que no les pareció bien que Papelucho mintiera, debido a que les enseñaron desde pequeñas a decir la verdad. Aun así, sienten que el personaje encanta desde todas sus aristas. Otro ejemplo clave es la evidencia de una estudiante que es capaz de asociar elementos del perfil del protagonista con su propia realidad, transformándolo en un personaje creíble y auténtico, que porta claramente la identidad de un niño de la edad de las lectoras (ver figura 2 Es. E 21).

\section{Conclusiones}

Las experiencias de lectura de las alumnas en relación con Mi hermano hippie, por Papelucho pasan por cómo está escrito el texto. Esto reafirma la idea de que la calidad y pertinencia de una obra literaria infantil no se determina por el tema. En esta novela, así como en la serie, la voz y perspectiva narrativas se combinan con la intertextualidad genérica, específicamente, el diario de vida, lo que resulta atractivo para las estudiantes y no entraña dificultad, pues logran distinguirlo de la instancia autoral: las alumnas son capaces de reconocer que están leyendo una narración ficcional y no un diario. Las niñas se identificaron gratamente con la escritura del diario de vida, a la vez que les parece una práctica inusual por parte de niños (género masculino). Esta cercanía de las alumnas con el diario les permite ser empáticas con el personaje en su necesidad de resguardar un espacio síquico y físico privado.

No obstante el año de publicación de la obra, como todo gran clásico, resiste el paso del tiempo. Las estudiantes se identifican con la forma de hablar del protagonista, asimilándola a un discurso infantil. 


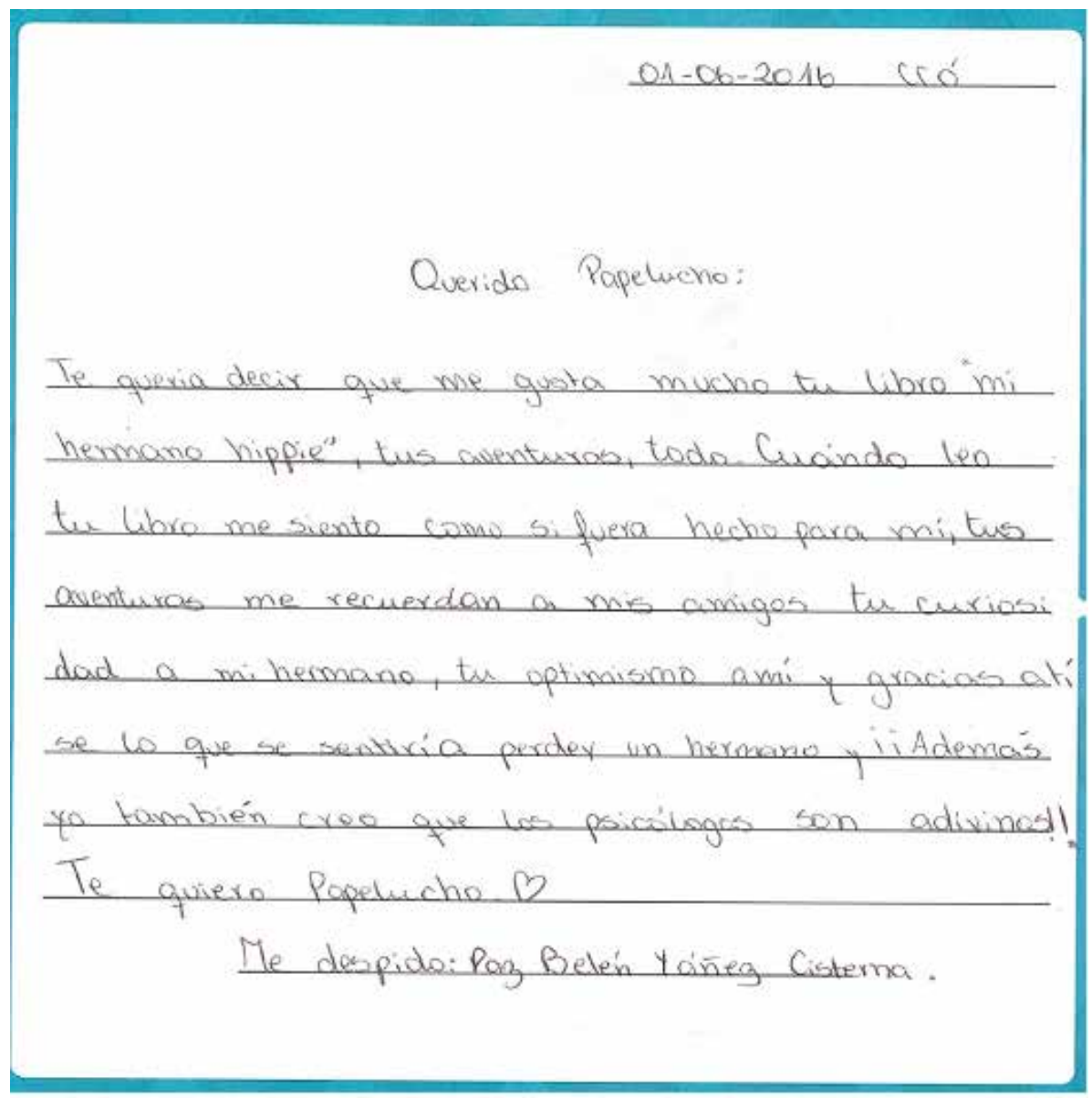

Figura 2. Carta elaborada por estudiante a Papelucho.

Fuente: elaboración propia.

La obra de Marcela Paz consigue tal recepción no a pesar del lenguaje, sino por el lenguaje, el que genera experiencias de lectura que las alumnas expresan verbalmente y afirman a través de su gestualidad. Las estudiantes asocian el lenguaje de la obra al registro coloquial y a una forma infantil y chilena de habla. El tratamiento léxico-semántico otorga un sello al personaje y a la obra, a la vez que trasunta una identidad infantil y cultural. Los neologismos, como comprobamos en la investigación, en lugar de ser un escollo, aportan a la lectura, pues las alumnas le asignan significado en el contexto semántico y, al ser un mecanismo característico del desarrollo del lenguaje infantil, incide en el efecto que produce el discurso de Papelucho en las niñas cuando dicen que se parece a un niño de verdad. Así también ocurre con las incorrecciones idiomáticas, lo que no es muy frecuente encontrar en la literatura infantil. El chilenismo, por su parte, contribuye a que las niñas se sientan identificadas con el habla en tanto variedad geográfica, a la vez que le otorga concreción cultural al discurso, la historia y los personajes. La variedad histórica de la lengua no resulta determinante para la comprensión, pues no fue obstáculo durante la lectura ni las alumnas lo consideraron como tal. Así, en su conjunto, el lenguaje contribuye a crear el efecto de verosimilitud del discurso infantil, favoreciendo la empatía y simpatía con el personaje. El crítico y escritor Manuel Peña Muñoz, al referirse a Papelucho señala: "al niño uno lo siente vivo porque está escrito desde dentro. Eso no sé cómo lo hizo ella, me gustaría saberlo. Lo hizo de una manera genial" (тVN, 2002, en línea). Pues bien, el estudio nos permite comprender de mejor manera aquello 
en que radica ese efecto, con base en la recepción de la obra en el proceso de lectura.

En conexión con el lenguaje, la novela consigue un efecto humorístico que funciona de manera similar en toda la serie. En la investigación pudimos corroborar que el humor virtual, en tanto despliegue de recursos de lenguaje, se concreta en la recepción de la obra por parte de las alumnas. Esto se manifiesta tanto en sus expresiones verbales como no verbales, con sus sonrisas y risas. Cuando las estudiantes afirman que les gustó el libro, la mayoría menciona situaciones o dichos que les resultaron graciosos, de modo que el humor es un aspecto importante en el interés que despierta la obra y, podríamos pensar, en el incentivo a la lectura durante la niñez. Las situaciones en las que vemos funcionar un humor leve les parecen irrisorias a las alumnas. En tales momentos, se contrasta lo serio y lo cómico, lo que en ocasiones les resulta extraño y divertido. Así también, el pensamiento ingenuo de los personajes infantiles, especialmente el de Papelucho, es algo que las mueve a risa, al igual que algunas incorrecciones léxicas. Esta es una de las razones a las que obedece la edad de lectura que recomendamos, de modo que los niños aprecien mejor el humor de la obra. También producen efecto humorístico los chascos provocados por la ignorancia o torpeza de los personajes, los que sí pueden causar risa a niños menores.

Aunque el humor resulta interesante para las niñas, ellas también se refieren a diversos aspectos serios que valoran y les parecen de interés, como la conciencia social del personaje, su afán de justicia y generosidad. Por tanto, en base a esto, es posible pensar que combinar lo serio y humorístico llega bien a los niños, pues la obra no subestima a sus lectores, sino que los considera como personas con derecho al mundo sin perder el juego y la risa. Al respecto, ante la pregunta por la perduración de la serie, el crítico literario Darío Oses responde: "porque siendo [Papelucho] un personaje en apariencia muy sencillo tiene una gran complejidad, una gran riqueza" (TVN, 2002, en línea).
Las alumnas reconocen el efecto emotivo que les produce el libro, efecto que incide en la valoración de la obra. En el caso del texto leído, las características discursivas y el contenido asociado a la historia generan sentidos y emociones que, en definitiva, conforman las experiencias de lectura. Como pudimos apreciar, hay situaciones de la historia y del discurso de los personajes que vinculan a las niñas con sus vivencias y sentimientos, así como con su entorno social. De esta manera, la obra no muestra la niñez como una abstracción idílica, sino con la diversidad que la caracteriza.

La configuración del personaje explica en gran medida el vínculo de las lectoras con la obra. Papelucho provoca un alto grado de identificación por su discurso, sus acciones y su forma de pensar. Creemos importante hacer notar que la diferencia social entre el protagonista y las lectoras no afecta la percepción positiva ni la identificación con el mundo infantil. Las niñas opinan que Papelucho se parece a ellas, pero que también es distinto, pues le reconocen singularidades excéntricas. Papelucho logra ser un personaje entrañable porque resulta verdadero, un niño común a la vez que singular. Las alumnas destacan de su personalidad el ser amistoso, sincero, simpático, travieso, aventurero. La caracterización del personaje implica un ejercicio de comprensión e interpretación, pues los rasgos no corresponden a descripciones del texto, sino al perfil que las alumnas construyen del personaje en base a su actuar y su decir. Al igual que personajes de la literatura infantil que han trascendido, como Tom Sawyer, Hucklberry Finn, Pinocho, Peter Pan, Ana de la Tejas Verdes, Pipi Calzaslargas, Max de Donde viven los monstruos, entre otros, Papelucho es un niño desacomodado con respecto al modelo de niño que ha pretendido inculcar el sujeto adulto desde una visión moralista y pedagógica restringida, lo que lo vuelve más convincente, cercano y atractivo.

A partir de los resultados de la investigación, podemos afirmar que es deseable que una obra literaria sea atractiva para los niños sin renunciar a su valor artístico. Más aún, es por esto que logra generar experiencia lectora, porque el espesor 
estético vehicula sentidos de manera implícita a través de la historia contada. En Papelucho no se subestima el mundo de los niños y se dialoga al mismo tiempo con el mundo de los adultos. Como todo verdadero clásico, logra trascender fronteras geográficas, porque el niño histórico y el niño universal (Soriano, 1995) se integran, de modo que la obra resulta humanamente verdadera. Ahora bien, este estudio nos muestra también que la conversación mediada favorece la reflexión sobre el texto y a partir del texto. En consecuencia, favorece las experiencias de lectura, idea que se corrobora con la valoración positiva tanto de la obra como de la actividad por parte de las alumnas.

Esta investigación genera nuevas preguntas y motiva nuevas indagaciones sobre la recepción lectora de Papelucho. El estudio permitió obtener información sobre la lectura de la obra por parte de niñas, lo que resultó sumamente interesante, aun cuando originalmente no contemplaba este criterio de género para definir la muestra. $\mathrm{Al}$ respecto, es importante hacer notar que el género masculino del protagonista no incide negativamente en la identificación con el personaje, y aun cuando hay aspectos con los que las niñas no se identifican, estos les resultan atractivos. Surge entonces la pregunta sobre la recepción de la obra por parte de niños, de modo de comparar las lecturas y la valoración de la obra desde las diferencias de sexo y género. Así también emerge la interrogante por cómo los niños (de género masculino) leen y valoran obras en que la historia se centra en un personaje femenino.

Finalmente, esperamos que esta investigación invite a realizar más estudios sobre la recepción lectora de literatura, de obras clásicas y recientes, de diferentes verosímiles y géneros, con el fin de ir comprendiendo cómo leen los niños y jóvenes, qué les motiva, qué sentidos construyen, cómo valoran la obras, qué vínculos generan con su persona y su entorno, y cómo la cultura y la sociedad que los rodea y moldea inciden en los sentidos que construyen, entre otras muchas preguntas que suscita el diálogo entre literatura y lectura.

\section{Referencias}

Bombini, G. (2005). La trama de los textos. Problemas de la enseñanza de la literatura. Buenos Aires: Lugar.

Bisquerra, R. (2009). Metodología de la investigación educativa. Madrid: La Muralla.

Bronckart, J. P. (2007). Desarrollo del lenguaje y didáctica de las lenguas (Trad. Gabriela Brochier). Buenos Aires: Miño y Dávila Editores.

Cerrillo Torremocha, P. (2015). LIJ. Literatura mayor de edad. Cuenca: Ediciones de la Universidad de Castilla-La Mancha.

Cifuentes Becerra, E. (2011). Marcas discursivas y narrativas del humor leve en Papelucho. Literatura $y$ Lingüística, 24, 15-32.

Colomer, T. (2010). Andar entre libros: la lectura literaria en la escuela. México: Fondo de Cultura Económica.

Cuesta, C. (2006). Discutir sentidos. Buenos Aires: Libros del Zorzal.

Chambers, A. (2014). Dime: los niños, la lectura y la conversación (Trad. Ana Tamarit Amieva). México: Fondo de Cultura Económica.

Cheetham, D. (2016). Dahl's Neologisms. Children's Literature in Education, 47, 93-109. Doi: 10.1007/ s10583-015-9254-2

Culler, J. (1979). La poética estructuralista. Barcelona: Anagrama.

Eco, U. (1981). Lector in fabula: la cooperación interpretativa en el texto narrativo. Barcelona: Lumen.

Fuguet, A. (1 de diciembre de 2001). Un chico subversivo. El País. Recuperado de http://elpais.com/diario/2001/12/01/babelia/1007167157_850215.html

Ibaceta Gallardo, I. (2016). El cuerpo del niño en Papelucho de Marcela Paz: voz y cronotopo infantil. En C. Andrade, I. Ibaceta, A. Troncoso y C. Valenzuela (eds.), Literatura para infancia, adolescencia y juventud: reflexiones desde los estudios literarios (pp. 65-80). Santiago: Editorial Universitaria.

Iser, W. (1987). El acto de leer (Trad. J. A. Gimbernat y Manuel Marbeito). Madrid: Taurus Ediciones.

Larraín, A. M. (2009). Marcela Paz: una imaginación sin cadenas. Santiago: Editorial Universitaria.

Lomas, C. y Mata, J. (2014). La formación de lectores de textos literarios. Textos de Didáctica de la Lengua y Literatura, 66, 5-7. 
Lluch, G. (2010). Cómo seleccionar libros para niños y jóvenes. Los comités de valoración en las bibliotecas escolares públicas. Gijón, España: Ediciones Trea.

Mcmillan, J. y Schumacher, S. (2005). Investigación educativa: una introducción conceptual ( $5^{\circ} \mathrm{ed}$., Trad. Joaquín Sánchez Baides). Madrid: Pearson.

Mendoza Fillola, A. (2004). La educación literaria. Bases para la formación de la competencia lecto-literaria. Málaga: Ediciones Aljibe.

Munita, F. (2011). La lectura mediada de literatura infantil como herramienta para la alfabetización emocional. Estudios pedagógicos, XXXVII (1), 269-277.

Paz, M. (2014). Mi hermano hippie, por Papelucho. Santiago: Editorial SM.

Paz, M. (1997). Papelucho casi huérfano. Santiago: Editorial Universitaria.

Pérez Serrano, G. (2004). Modelos de investigación cualitativa en educación social y animación sociocultural: aplicaciones prácticas. Madrid: Narcea.

Rodari, G. (2012). Gramática de la fantasía. Introducción al arte de inventar historias (Trad. Mario Merlino). Barcelona: Editorial Planeta.
Rosemblatt, L. M. (2002). La literatura como exploración (Trad. Victoria schussheim). México: Fondo de Cultura Económica.

Ruiz Olabuénaga, J. I. (2012). Metodología de la investigación cualitativa. Universidad de Deusto.

Sanjuán Álvarez, M. (2011). De la experiencia de la lectura a la educación literaria: Análisis de los componentes emocionales de la lectura literaria en la infancia y la adolescencia. Ocnos 7, 85-100.

Soriano, Marc (1995). La literatura para niños y jóvenes: Guía de exploración de sus grandes temas (Trad. Graciela Montes). Buenos Aires: Colihue.

Troncoso Araos, X. y Rubio, C. (2015). Antología crítica del relato infantil sudamericano. Concepción: Ediciones Universidad Católica del Maule y Sello Editorial Universidad de Concepción.

TVN (productor). (2002). El Papelucho de Marcela Paz. Show de los libros [programa de televisión]. Santiago, Chile. Recuperado de http://www.educarchile.cl/ech/ pro/app/detalle? ID $=183020$ 